\title{
Reversible phase transformation in polycrystalline TRIP steels induced by cyclic indentation performed at the nanometric length scale
}

\author{
J.J. Roa ${ }^{1,2, *}$, I. Sapezanskaia ${ }^{1,2,3}$, \\ G. Fargas ${ }^{1,2}$, R. Kouitat ${ }^{3}$, A. Redjaïmia ${ }^{3}$, A. \\ Mateo $^{1,2}$ \\ ${ }^{1}$ Department of Materials Science and Metallurgical Engineering, Universitat Politècnica de \\ Catalunya, Campus Diagonal Besòs-EEBE, Barcelona 08019, Spain. \\ 2 Centre for Research in Multiscale Engineering of Barcelona, Universitat Politècnica de \\ Catalunya, Campus Diagonal Besòs-EEBE, Barcelona 08019, Spain. \\ ${ }^{3}$ Institut Jean Lamour, UMR 7198 CNRS, Université de Lorraine, Nancy Cedex 54840, France \\ * corresponding author, e-mail: joan.josep.roa@upc.edu
}

Abstract: Metastable austenitic stainless steels are an interesting group of materials, which exhibit the TRansformation Induced Plasticity effect. In this regard, phase transformation from austenite to martensite enhances the work hardening of the metastable austenitic stainless steels affecting the deformation dynamics and mechanical properties including fatigue properties. Within this context, the reversible load-induced phase transformation from $\gamma$ to $\varepsilon$-martensite has been investigated at the local scale under cyclic indentation. This reversible phase transformation was manifested itself by a combination of hysteresis loops, elbow formation and reversible pop-ins in the loading curve. The initial cyclic achieved through the nanoindentation technique allowed to identify three different deformation regime for the $<111>$ austenitic grains. At the first step, the dislocation activation producing a softening effect took place, subsequently the phase transformation induced a hardening effect, finally, a plateau was reached where no more plastic deformation was observed.

Keywords: metastable austenitic stainless steels; nanoindentation; reversible phase transformation; cyclic indentation; plastic deformation mechanisms; shape memory effect. 


\section{Introduction}

Metastable austenitic stainless steels are materials widely employed in the automotive industry due to their distinguished mechanical properties [1]. In this sense, the mechanical behavior is governed by a conjunction of multiple deformation mechanisms, whereby the most decisive might be the TRansformation Induced Plasticity (TRIP), which is widely used to denote the austenite-to-martensite phase transformation. Thereby, this transformation can be direct (from $\gamma$ to $\alpha$ ) or indirect via the intermediate hexagonal phase (from $\gamma$ to $\varepsilon$-martensite) $[2,3,4,5]$. The phase transformation effect on metastable austenitic stainless steels depends highly on the Stacking Fault Energy (SFE) $[6,7]$. The compositional dependence of the alloy is an important factor affecting SFE and it can be determined by using the empirical equation proposed by Schramm and Reed [8]:

SFE $=-53+6.2(\mathrm{Ni})+0.7(\mathrm{Cr})+3.2(\mathrm{Mn})+9.3(\mathrm{Mo})$

where SFE is in $\mathrm{mJ} \cdot \mathrm{m}^{-2}$ and the elements present in equation (1) are in mass $\%$. Thin $\varepsilon$-martensite plates can be formed easily from planar austenitic defects, since its structure corresponds to an overlapping of intrinsic stacking fault (SF) on every second $\{111\}$ plane as reported in Refs. $[9,10]$. The reversible phase transformation $(\gamma \Leftrightarrow \varepsilon)$ is well exploited in shape memory alloys such as $\mathrm{TiNi}$ [11] or Fe-Mn-Si-Cr [12]. On the other hand, in Fe-Ni-Cr based metastable austenitic stainless steels, $\varepsilon$-martensite is considered as unstable transition phase, which further transforms to $\alpha^{\prime}$-martensite $[13,14]$. In this regard, $\varepsilon$ martensite may be considered as a dislocation pile-up of intrinsic stacking faults (SFs) on every second (111) austenite plane, the $\gamma \Rightarrow \varepsilon$ transformation is a rather simple process. Recently, Roa et al. [15] observed the $\gamma \Rightarrow \varepsilon$ martensitic phase transformation in highly sheared austenitic zones, mainly located at the grain boundary.

In this context, the aim of the present paper is to locally study and correlate the shape and the different bursts of the cyclic loading-unloading curves by means of the nanoindentation technique. The reversible phase transformation will be investigated in order to allow better understanding of the $\gamma \Rightarrow \varepsilon$ martensitic transformation for metastable austenitic stainless steels. 


\section{Experimental procedure}

The material investigated in this work was a commercial annealed AISI 301LN stainless steel at $1100^{\circ} \mathrm{C}$ for $1 \mathrm{~h}$, equivalent to EN 1.4318, supplied by Outokumpu (Finland) as $2 \mathrm{~mm}$ thick sheets. The chemical composition is shown in Table 1. Prior the microstructural and micromechanical characterization, the TRIP steel specimens were polished with silicon carbide and then diamond suspension of $30,6,3$ and $1 \mu \mathrm{m}$. Finally, a neutral suspension of $20 \mathrm{~nm}$ alumina particles was used in order to remove possible work hardening introduced during surface preparation. The average grain size for the austenitic phase was directly determined by the linear intercept method yielding a monomodal austenitic equiaxial grains distribution, whose sizes are $12.0 \pm 2.4 \mu \mathrm{m}$.

The ultra-nanohardness tester (UNHT) from CSM instruments using a Berkovich tip indenter was employed to perform cyclic nanoindentation tests working under loading mode at a maximum applied load of $6 \mathrm{mN}$. The indenter shape has been carefully calibrated for true indentation depth as small as 20 $\mathrm{nm}$ by indenting fused silica samples of known Young's modulus (72 GPa). Furthermore, the loading and unloading rates were held constant and equals to $15 \mathrm{mN} \cdot \mathrm{min}^{-1}$ for all the tests.

\section{Results and discussion}

Loading-unloading (P-h) curves for 50 cycles are depicted in Figure 1a, which were conducted between $10 \%$ of the peak working under load control mode and $6 \mathrm{mN}$ of maximum applied load. In this representation, each cycle has been shifted $10 \mathrm{~nm}$ in order to observe the real cycle shape. A pop-in or a sudden displacement-burst (see black arrow) at constant load of around $0.2 \mathrm{mN}$ is evident in the first loading cycle. As it is well stablished in the Hertzian contact theory [16], prior to the first pop-in, the deformation behavior is purely elastic. This phenomenon is well understood for a wide variety of materials (e.g. metals, ceramics, coatings, etc.) and it may be related mainly to the first stage where the sample initially undergoes a plastic deformation as found in Refs. $[17,18,19,20,21,22]$. As it is evident in this representation, no stress relaxation or softening mechanisms takes place due to all the P-h cycles reach the same maximum applied load, around $6 \mathrm{mN}$. A magnification of several loading- 
unloading cycles $(\mathrm{N})$ is represented in Figure $\mathbf{1 b}$, where the maximum deformation takes place for the initial P-h cycles; when the indentation cycle increases, the aperture of the P-h cycles decreases. At the macroscopic length scale, when the TRIP steels are investigated under conventional dynamic tests, a similar phenomenon is appreciated $[23,24,25,26,27,28,29]$, which is mainly attributed to the ratcheting strain accumulation effect. Within this context, the open loops for low cyclic cycles may be described as a consequence of increasing the dislocation activity during the indentation process. The width between the loading and unloading curve decreases until reaching a saturation level after 30 indentation cycles from which it remains invariant. This trend highlights the difficulty to activate the dislocation motion for the same applied stress. For this reason, the P-h curve presented in Figure 1a does not present a softening or hardening effect.

The load-displacement curves exhibit multiple small serrations as clearly evident in Figure $\mathbf{2 b}$ referred as pop-ins and pop-outs to occur during loading and unloading, respectively and are clearly observed for the $<111>$ austenitic grains as shown in Figure 2.

Figure 2a, illustrates a cyclic load-penetration depths curve conducted under loading control mode between $10 \%$ of the peak loading value and the maximum applied load, $6 \mathrm{mN}$. As it is evident, a large plastic deformation takes place during the initial cycle followed by a fully elastic behavior for cycles 2 to 7 where the maximum stress applied remains constant and no softening or hardening mechanisms takes place. Afterwards, the aperture at the center of the P-h curves started to increase for the subsequent cycles (from cycle 7 to 10), where a softening effect takes place followed by a hardening behavior above cycle 11 , labelled as $\mathrm{S}$ and $\mathrm{H}$, respectively in Figure $\mathbf{2 a}$.

In the bottom part of the P-h curve for cycles 6 and 8 the unloading curve abnormally bends and the loading and unloading curve intersect at that point (see dash circles and labelled as (1) and (2)). This gradual change in the slope is well known as elbow, which indicates an activation of a reversible plasticity or pseudoplasticity. This phenomenon, which is well studied and understood for $\mathrm{Si}$ and other semiconductor materials at the nanometric length scale, had never been observed before for TRIP steels. This behavior can be related to three 
different factors: (i) reversible amorphization under load [30,31,32], (ii)

131 annealing treatments [33], and (iii) reversible phase transformation

$132[34,35,36,37]$. Pan et al. [11] by means of cyclic nanoindentation tests on NiTi shape memory alloys observed the same phenomenon described above, which may be related to stress-induced martensitic transformation during the unloading process. This reversible transformation was accompanied by an anelastic re-loading curves with elbow formations, such as those observed in

Figure 2a. As it is evident in this figure, a change of material response under cyclic indentation takes place during the $9^{\text {th }}$ cycle, while during the previous cycles the behavior is fully reversible. Furthermore, the deformation induced during the first indentation cycle contributes to increases the critical stress for further slip and phase transformation, which becomes more favorable during the subsequent P-h cycles. This observation is similar to that observed for the cycle 9 and 11, just after the elbow observation. A magnification of several open P-h cycles, showing an anelastic behavior, which may be related to the reversible phase transformation, $\gamma \Leftrightarrow \varepsilon$, during the loading process is depicted in Figure 2b. The shape memory effect might be too weak to be observed for TRIP steels by conventional cyclic techniques. However, cyclic nanoindentation technique induces dislocation motion as well as shear bands for TRIP steels, favoring the phase transformation over dislocation slip [38]. Furthermore, it facilitates reversible $\gamma \Leftrightarrow \varepsilon$ transformation, rather than $\gamma \Rightarrow \alpha^{\prime}$ or even $\varepsilon \Rightarrow \alpha^{\prime}$ transformation. After the second elbow (labelled as (2)), and anelastic behavior takes places. After that, the cycle is open and a high density of pop-ins and pop-outs are clearly visible, as depicted in Figure $\mathbf{2} \mathbf{b}$ and also in inset of Figure 2c. Furthermore, above the $11^{\text {th }}$ cycle, a hardening mechanisms is activated due to the plastic strain accumulated during the previous cyclic P-h curves [39] as well as the direct $\alpha^{\prime}$-martensite transformation from $\gamma$ without $\varepsilon$-martensite as reported in Ref. [40]. After the $12^{\text {th }}$ cycle, the P-h curve did not exhibit any major shape change. On the other hand, the maximum applied load in each subsequent cycle slightly increases and the pop-ins and pop-outs become more pronounced.

In Figure 2c, the experimental as well as the modified curves (where the popins and pop-outs are removed and the continuous parts of the P-h curve are 
stitched together) of the last P-h cycle is represented. Both representations present a similar stiffness $\left(S=d P / d h \approx 0.14 \mathrm{mN} \cdot \mathrm{nm}^{-1}\right)$ without elbow phenomena. The inset exhibits a magnification of the P-h curve, where the popins and pop-outs are clearly discerned. Furthermore, the sum of all pop-ins is around the same that the sum of the different pop-outs, $\Sigma \Delta \mathrm{h}_{\text {pop-in }} \approx \Sigma \Delta \mathrm{h}_{\text {pop-out }} \approx$ $25 \mathrm{~nm}$. This finding indicates that the dislocations generated during the loading process are annihilated during the unloading one emitted from the contact edge between the Berkovich indenter and the $<111>$ austenitic grain. Furthermore, it is found that the load after each pop-in is relatively well described by the elastic loading equation $\left(P \approx C \cdot h^{3 / 2}[16]\right)$ which means that these pop-ins are not related to the elasto-to-plastic transition. It is reasonable to assume that those pop-ins events have a different origin, mainly related to phase transformation. Furthermore, the appearance of the different pop-ins observed in the loading curve indicates the occurrence of several deformation mechanisms at a constant displacement, such as reversible dislocation gliding or by reversible phase transformation. Pop-ins arising beyond the elasto-to-plastic transition in TRIP steels have been observed by several authors under monotonic tests at the nanometric length scale and are often attributed to phase $\gamma \Rightarrow \alpha^{\prime}$ phase transformation $[41,42]$. Thus, as it is depicted in Figure 2c, the different pop-ins are reversible. The similar trend was observed by Ahn et al. [43], where multiple pop-ins were observed in the loading curve and these features were attributed to the $\gamma \Rightarrow \varepsilon$ transformation observed by transmission electron microscopy (TEM). It is worth to mention that in austenitic stainless steels the mechanically induced formation of $\varepsilon$-martensite is reported to occur when the SFE is below $18 \mathrm{~mJ} \cdot \mathrm{m}^{-2}$ [44], which is the case of the material studied in this work (SFE=7.87 $\left.\mathrm{mJ} \cdot \mathrm{m}^{-2}\right)$.

Within this context, the $\gamma \Rightarrow \varepsilon$ phase transformation under loading is the most widely reported reason for occurrence of pseudoelasticity in iron-based shape memory alloys $[45,46,47,48]$, where the pseudoelasticiy phenomenon is mainly observed during the cyclic loading process as reported in Refs. [12,49]. This phenomenon is mostly attributed to the reversible transformation $(\gamma \Leftrightarrow \varepsilon)$ under load, which can be triggered strain-induced plasticity at room temperature, particularly in alloys with low stacking fault energy, SFE [49,50,51]. On the other 
hand, the deformation-induced $\varepsilon$-martensite formation in alloys with a low $\mathrm{Ni}$ content (see Table 1) has been reported to be rather unstable [52].

The transformation between $\gamma$ and $\varepsilon$ is expected to easy occur, while the $\varepsilon \Rightarrow \alpha^{\prime}$ martensitic transformation requires a higher activation energy. Thus, the different pop-ins observed in the loading curve, Figure $\mathbf{2 c}$, may be related to the phase transformation from $\gamma$ to $\varepsilon$, while the $\varepsilon \Rightarrow \alpha^{\prime}$ martensitic transformation is practically impossible to occur due to the stress generated during the indentation process, which is not high enough to induce this transformation. Furthermore, the pop-outs observed during the unloading process may be related to the reversible phase transformation (from $\varepsilon$ martensite to $\gamma$ ). On the other hand, Sekeido et al. [53] observed multiple popins in the loading curve which were attributed to the $\varepsilon$-martensite formation.

However, as can be withdrawn from Figure $\mathbf{2} \mathbf{d}$, there is a correlation between the cycle number with the average pop-in width $\left(\Delta h_{\text {pop-in }}\right)$ and the accumulative displacement due to the different pop-ins during the loading cycle $\left(\sum \Delta h_{p o p-i n}\right)$. As it is evident in this representation, the $\Delta h_{p o p-i n}$ increases steadily, almost doubling the initial value; from $0.54 \mathrm{~nm}$ in the cycle number 10 to $0.97 \mathrm{~nm}$ in the cycle number 90 . On the other hand, the total displacement increases more than three times, from 8.15 to $26.1 \mathrm{~nm}$; especially at the initial stage, not only the width but also the number of pop-ins increases. Around the $90^{\text {th }}$ cycle a saturation is reached as confirmed also by the stabilization of the hysteresis shape observed in Figure 2d. This observation, may be related to the accumulated plastic features induced along the entire cyclic process. According to Ahn and co-workers [43], the width of the different pop-ins, may be considered as the projection of the slip systems of Shockley partial dislocations, leading to the $\varepsilon$-martensite formation. In this regard, at least two SF are required for the formation of a $\varepsilon$-band, with a respective unit displacement of around 0.1 $\mathrm{nm}$ depending on the certain slip system. Thus, $\Delta \mathrm{h}_{\text {pop-in }}$ reported in this study corresponds to the formation of around five to ten $\varepsilon$-platelets.

Nanoindentation technique was successfully used to identify the different deformation regimes. In this regard, the plot of the cyclic area versus cycle for the first 20 cycles is shown in Figure $\mathbf{2 e}$ where three different regions are 
visible. This trend may be related with the plastic deformation features activated under the cyclic P-h process. A softening effect (Region 1) followed by a hardening one (Region 2) is clearly evident. In the first region, the softening behavior is related to the activation of negative dislocation sources emitted from the contact edge of the Berkovich indenter, which reduces the dislocation density in the deformed area and causes a local softening. This phenomenon may be related mainly to a direct phase transformation to $\alpha$ - without $\varepsilon^{-}$ martensite, as reported by Tian et al. [54]. Finally, when the phase transformation has been activated and the region deformed reaches the maximum accumulated strain under the Berkovich indenter (around 12 cycles), no more deformation features are able to be activated at the same time, for this reason, the cyclic area reaches a plateau.

In order to observe the dislocation motion during the holding process cyclic indentation loading tests with large maintaining time between loads were done. Figure 3 shows the applied load $(P,(m N)$ ) (the specimen was loaded and unloaded between 0 and $6 \mathrm{mN}$ in steps of $0.6 \mathrm{mN}$ and a holding time between each step of $1800 \mathrm{~s}$ was implemented) and penetration depth $(\mathrm{h},(\mathrm{nm}))$ as a function of time. It is clearly seen that the penetration depth increases with increasing time for each holding step and the opposite occurred during the unloading process. On the other hand, the total amount of displacement at maximum load and fully unload is quite similar, being the maximum displacement at a maximum applied load of around $248 \pm 3 \mathrm{~nm}$, while the cumulative viscoplastic displacement is around $64 \pm 2 \mathrm{~nm}$.

\section{Conclusions}

Cyclic nanoindentation tests in austenitic stainless steels have been performed in order to examine the correlation between the loading and unloading features (i.e. shape, pop-ins, pop-outs, etc.) and the reversible phase transformation.

(i) The metastable austenitic stainless steel, AISI 301 LN, can undergoes a reversible $\gamma \Leftrightarrow \varepsilon$ martensitic phase transformation.

(ii) The phase transformation was anisotropic, being the $<111>$ austenitic grain parallel to the loading axis, the most favorable. 
(iii) The reversible phase transformation has not been observed at the macroscopic length scale tests due to the fact that phase transformation has been found highly anisotropic.

(iv) Reversible phase transformation manifested in the loading-unloading curve by a combination of several features; hysteresis loops, elbow formation and reversible pop-ins in the loading curve.

\section{Acknowledgements}

Dr. I. Sapezanskaia would like to thanks DOCMASE program for its financial support. The authors would like to acknowledge the financial support from the Spanish Government through the project MAT2015-70780-c4-3-P.

\section{References}

[1] Ultralight Steel auto body, ulsab final report, tech. rep., American Iron and Steel Institute, Washington, D. C., March 1998.

[2] M. Humbert, B. Petit, B. Bolle and N. Gey: Mater. Sci. Eng. A, 2007, vol. 454-455, pp. 508-517.

[3] J. Talonen, P. Nenonen, G. Pape and H. Hänninen: Metall. Mater. Trans. A, 2005, vol. 36, pp. 421-432.

[4] V. Tsakiris and D. V. Edmonds: Mater. Sci. Eng. A, 2005, vol. 36, pp. 421432.

[5] J. Venables: Philos. Mag., 1961, vol. 7, pp. 35-44.

[6] J. Talonen and H. Hänninen: Acta Mater., 2007, vol. 55, pp. 6108-6118.

[7] S. Tavares, J. Pardal, M. G. da Silva, H. Abreu and M. da Silva: Mat. Charact., 2009, vol. 60, pp. 907-911.

[8] A. Di Schino, M. Barteri and J. M. Kenny: J. Mater. Sci. Lett., 2002, vol. 21, pp. 751-753.

[9] J. A. Venables: Philos. Mag., 1962, vol. 7, pp. 35-44.

[10] J. W. Brooks, M. H. Loretto and R. E. Smallman: Acta Metall., 1979, vol. 27, pp. 1829-1838.

[11] G. Pan, Z. Cao, M. Wei, L. Xu, J. Shi and X. Meng, Mater. Sci. Eng. A, 2014, vol. 600, pp. 8-11. 
[12] A. Baruj, G. Bertolino and H. E. Troiani: J. Alloys Compd., 2010, vol. 502, pp. 54-58.

[13] P. L. Mangonon and G. Thomas: Metal. Trans., 1970, vol. 1, pp. 15771586.

[14] V. Seetharaman and P. Krishman: J. Mater. Sci., 1981, vol. 16, pp. 523530.

[15] J. J. Roa, J. M. Wheeler, T: Trifonov, G. Fargas, A. Mateo, J. Michler and E. Jiménez-Piqué: Mat. Sci. Eng. A, 2015, vol. 647, pp. 51-57.

[16] H. R. Hertz: J. Reine. Angew. Math., 1896, vol. 92, pp. 156-171.

[17] T. -H. Ahn, C. -S. Oh, D. H. Kim, K. H. Oh, H. Bei, E. P. George and H. N. Han: Scr. Mater., 2010, vol. 63, pp. 540-543.

[18] T. Ohmura and K. Tsuzaki: J. Mater. Sci., 2007, vol. 42, pp. 1728-1732.

[19] H. Bei, Y. F. Gao, S. Shim, E. P. George and G. M. Pharr: Phys. Rev. B, 2008, vol. 77, pp. 060103/1-060103/4.

[20] A. C. Fisher-Cripps, Nanoindentation, 2nd ed. New York, United States of America: Springer-Verlag Press; 2004, 3, 9-10.

[21] E. Jiménez-Piqué, Y. Gaillard and M. Anglada: Key Eng. Mater., 2007, vol. 333, pp. 107-116.

[22] J. J. Roa, E. Jiménez-Piqué, X. G. Capdevila and M. Segarra: J. Eur. Ceram. Soc., 2010, vol. 30, pp. 1477-1482.

[23] F. Yoshida: Int. J. Press. Vessel. Pip., 1990, vol. 44, pp. 207-223.

[24] N. Ohno and M. Abdel-Karim: J. Eng. Mater. Technol., 2000, vol. 122, pp. $35-41$.

[25] D. Kujawski, V. Kallianpur and E. Krempl: J. Mech. Phys. Solids, 1980, vol. 28, pp. 129-148.

[26] Y. Mima and N. Ohno, Uniaxial ratchetting of 316 FR Steel at room temperature - Part I: Experiments 122 (2000) 29-34.

[27] E. Krempl and M. B. Ruggles: J. Mech. Phys. Solids, 1990, vol. 38, pp. 587-597.

[28] M. B. Ruggles and E. Krempl: J. Eng. Mater. Technol., 1989, vol. 111, pp. 378-383.

[29] J. R. Ellis, D. N. Robinson and C. E. Pugh: J. Eng. Mater. Technol., 1983, vol. 105, pp. 250-256. 
[30] V. Domnick, Y. Gogotsi and S. Dub: Appl. Phys. Lett., 2000, vol. 76, pp. 2214-2216.

[31] H. Huang and J. Yan: Scr. Mater., 2015, vol. 102, pp. 35-38.

[32] L. Chang and L. C. Zhang: Acta Mater., 2009, vol. 57, pp. 2148-2153.

[33] D. Lin and P. L. Lin: Microelectron. Reliab., 2016, vol. 56, pp. 66-72.

[34] Y. Gogotsi and V. Dominich: J. Mater. Res., 2000, vol. 15, pp. 871-879.

[35] D. J. Oliver, J. E. Bradby, S. Ruffell, J. S. Williams and P. Munroe: J. Appl. Phys., 2009, vol. 106, pp. 093509/1-093509/6.

[36] R. Rao, J. E. Bradby, S. Ruffell and J. S. Williams: Microelectronics J., 2007, vol. 38, pp. 722-726.

[37] J. II Jang, M. J. Lance, S. Wen and G. M. Pharr: Appl. Phys. Lett., 2005, vol. 86, pp. 1-3.

[38] I. Sapezanskaia, J. J. Roa, G. Fargas, M. Turon-Viñas, T. Trifonov, R. Kouitat Njiva, A. Redjaïmia and A. Mateo: Mat. Charact., 2017, vol. 131, pp. 253-260.

[39] Y. Mima and N. Ohno: J. Eng. Mater. Technol., 2000, vol. 122, pp. 29-34.

[40] Y. Tian, O. I. Gorbatov, A. Borgenstam, A. V. Ruban and P. Hedström: Metall. Mater. Trans. A, 2017, vol. 48, pp. 1-7.

[[41] R. D. K. Misra, P. Venkatsurya, K. M. Wu and L. P. Karjalainen: Mater. Sci. Eng. A, 2013, vol. 560, pp. 693-699.

[42] T. -H. Ahn, C. -S. Oh, D. H. Kim, K. H. Oh, H. Bei, E. P. George and H. N. Han: Scr. Mater., 2010, vol. 63, pp. 540-543.

[43] T. -H. Ahn, S. B. Lee, K. -T. Park, K. H. Oh and H. N. Han: Mater. Sci. Eng. A, 2014, vol. 598, pp. 56-61.

[44] S. Allain, J. P. Chateau, O. Bouaziz, S. Migot and N. Guelton: Mater. Sci. Eng. A, 2004, vol. 387-389, pp. 158-162.

45] T. Sawaguchi, L.-G. Bujoreanu, T. Kikuchi, K. Ogawa, M. Koyama and M. Murakami: Scr. Mater., 2008, vol. 59, pp. 826-829.

[46] S. Kajiwara and T. Kikuchi: Acta Metall. Mater., 1990, vol. 38, pp. 847-855.

[47] C. L. Li, D. J. Cheng and Z. H. Jin: Mater. Sci. Eng. A, 2002, vol. 325, pp. 375-379.

[48] H. Koohdar, M. Nili-Ahmadabadi, M. Habibi-Parsa and H. GhasemiNanesa: Avd. Mater. Res., 2014, vol. 829, pp. 25-29. 
[49] T. Sawaguchi, T. Kikuchi and S. Kajiwara: Smart Mater. Struct., 2005, vol. 14, pp. S317-S322.

[50] H. R. Koohdar, M. Nili-Ahmadabadi, M. Habibi-Parsa and H. R. Jafarian: Mater. Sci. Eng. A, 2015, vol. 621, pp. 52-60.

[51] X. Wang and C. Zhang: J. Mater. Sci. Lett., 1998, vol. 17, pp. 1795-1796.

[52] G. Blanc and R. Tricot: Rev. La Métallurgie, 1973, vol. 70, pp. 257-514.

[53] K. Sekeido, T. Ohmura, T. Sawaguchi, M. Koyama, H. W. Park and K. Tsuzaki: Scr. Mater., 2011, vol. 65, pp. 942-945.

[54] Y. Tian, O. I. Gorbatov, A. Borgenstam, A. V. Ruban and P. Hedström: Metall. Mater. Trans. A, 2017, vol. 48, pp. 1-7. 


\section{Figure captions}

Figure 1. (a) General view of the cyclic evolution of the P-h curves for 50 cycles performed under load control mode, which were conducted between the maximum applied load $(\approx 6 \mathrm{mN})$ and $10 \%$ of the peak working $(\approx 0.6 \mathrm{mN})$. The black arrow shows the pop-in which is attributed to the elastic-to-plastic transition and (b) detailed view of every tenth cycle. Between each cycle the penetration depth has been shifted $10 \mathrm{~nm}$ in order to observe better the shape of each P-h cycle.

Figure 2. (a) General view of the cyclic evolution of the P-h curves for 100 cycles performed under load control mode at a maximum applied load of $6 \mathrm{mN}$ for an annealed austenite $<111>$ grain. (b) Detailed view of every tenth cycle. Between each cycle the penetration depth has been shifted $15 \mathrm{~nm}$ in order to observe the shape of each P-h cycle. (c) Real and simulated (pop-in free) P-h curve for the last indentation cycle, 100. (d) $\sum \Delta \mathrm{h}_{\text {pop-in }}$ (blue) and $\Delta \mathrm{h}_{\text {pop-in }}$ (green) as a function of the cycle number and (e) Cyclic P-h area as a function of the cycle.

Figure 3. Multi-step nanoindentation testing with a holding period in each step holded constant and equals to $1800 \mathrm{~s}$. Applied $(\mathrm{P},(\mathrm{mN}))$ load ramp and resulting penetration depth $(\mathrm{h},(\mathrm{nm}))$ as a function of the time. 
(a)

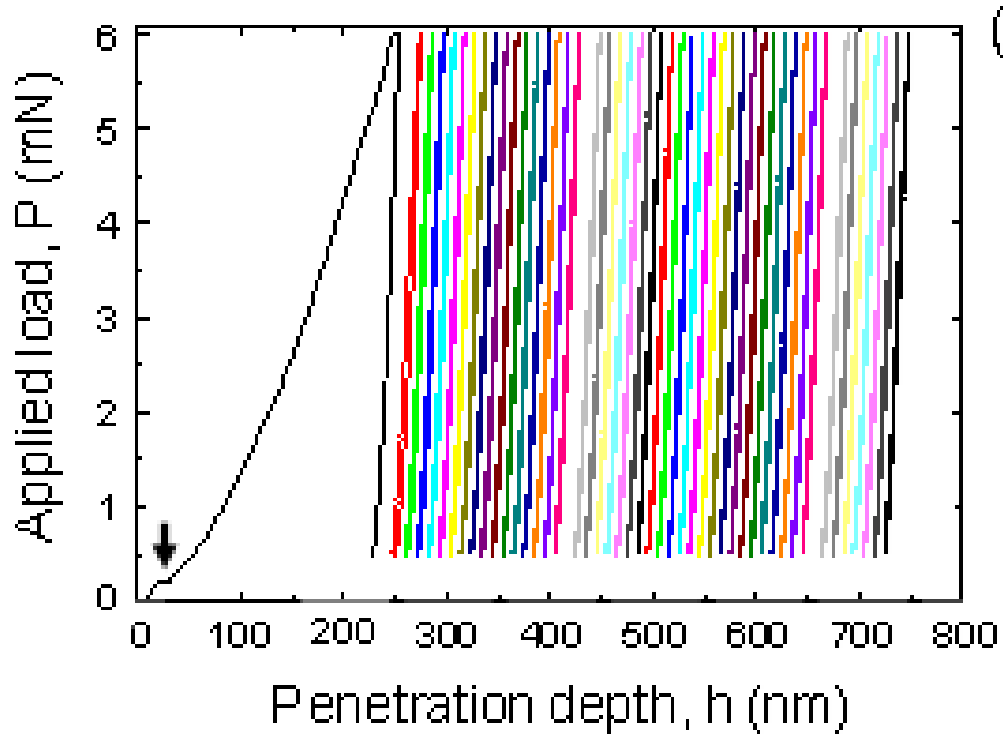

(b)

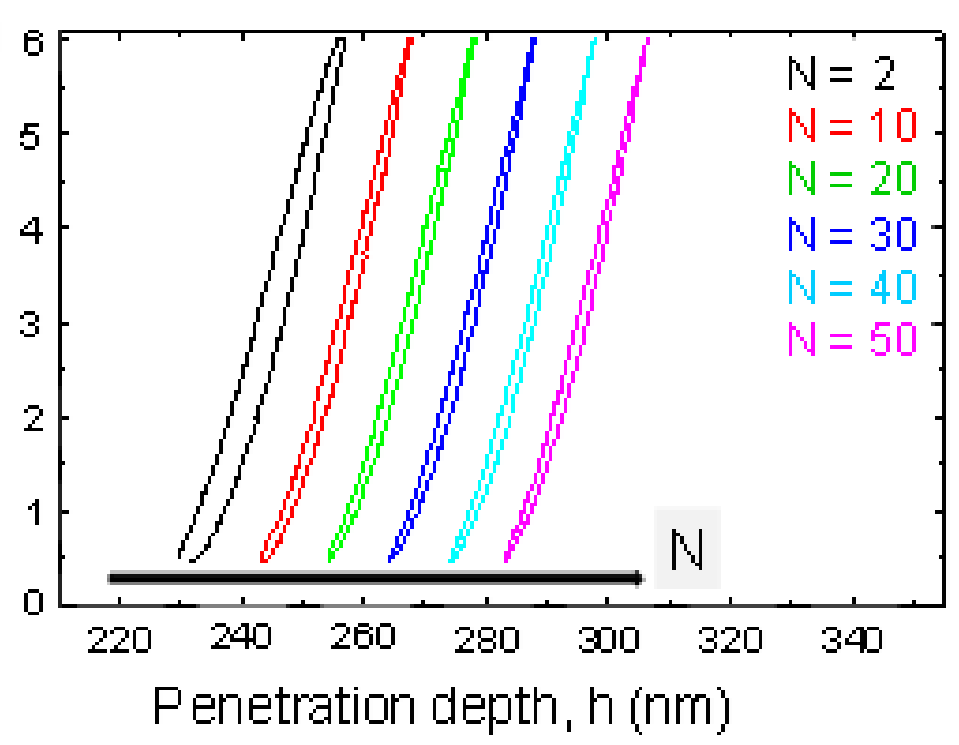


(a)

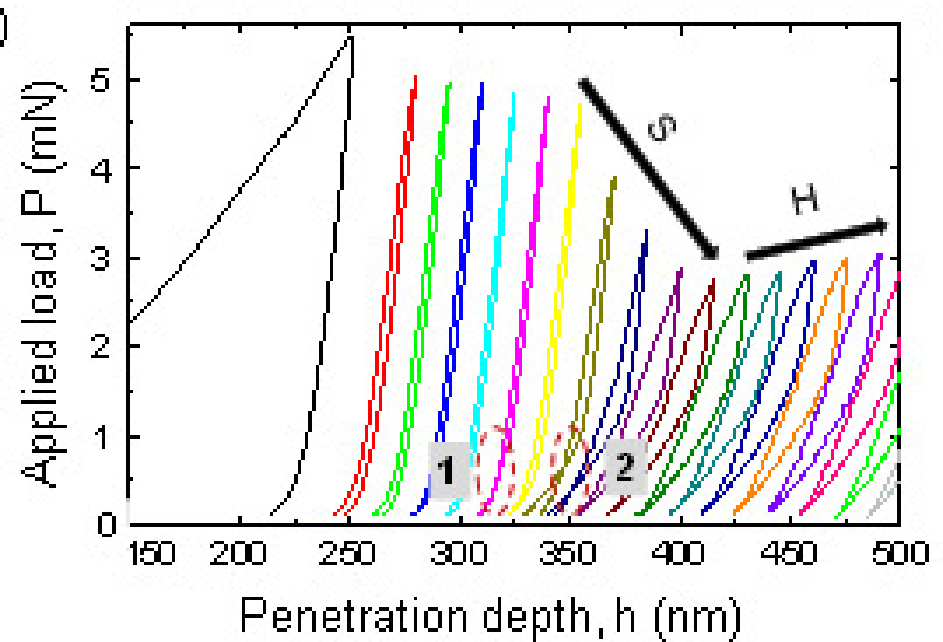

(c)

$\Sigma\left(\Delta \mathbf{h}_{\text {pop-hn }}\right)=25.54 \mathrm{~nm} \quad \Sigma\left(\Delta \mathbf{h}_{\text {pop-out }}\right)=2582 \mathrm{~nm}$

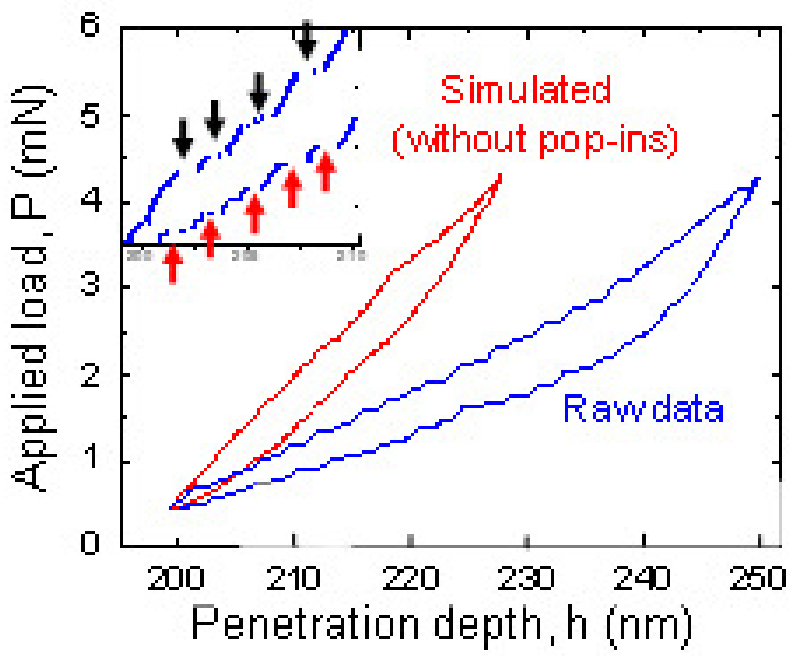

(b)

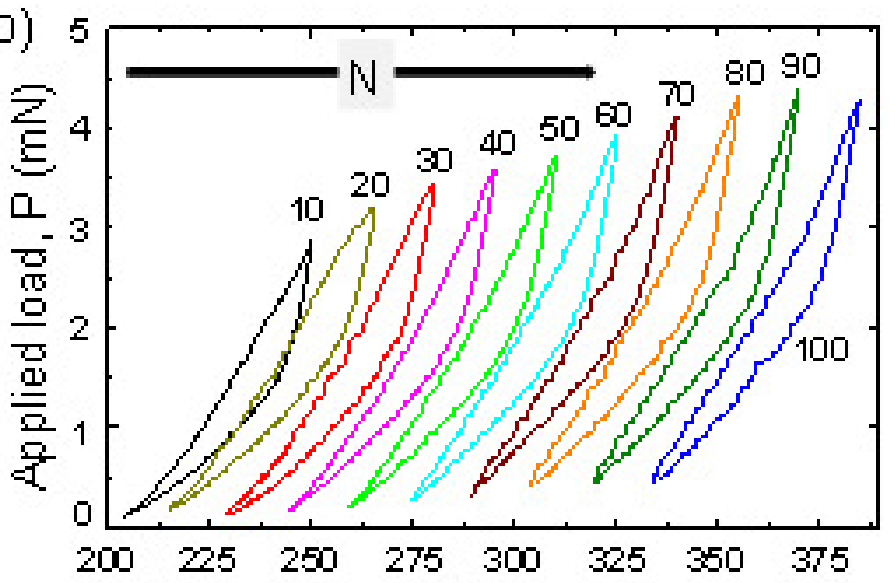

Penetration depth, h $(\mathrm{nm})$

(d)

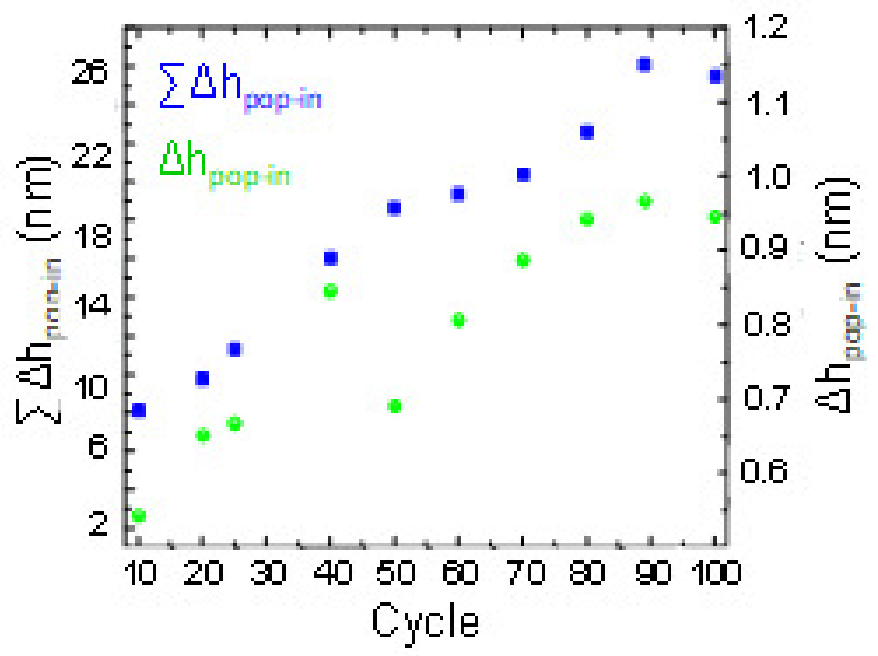

(e)

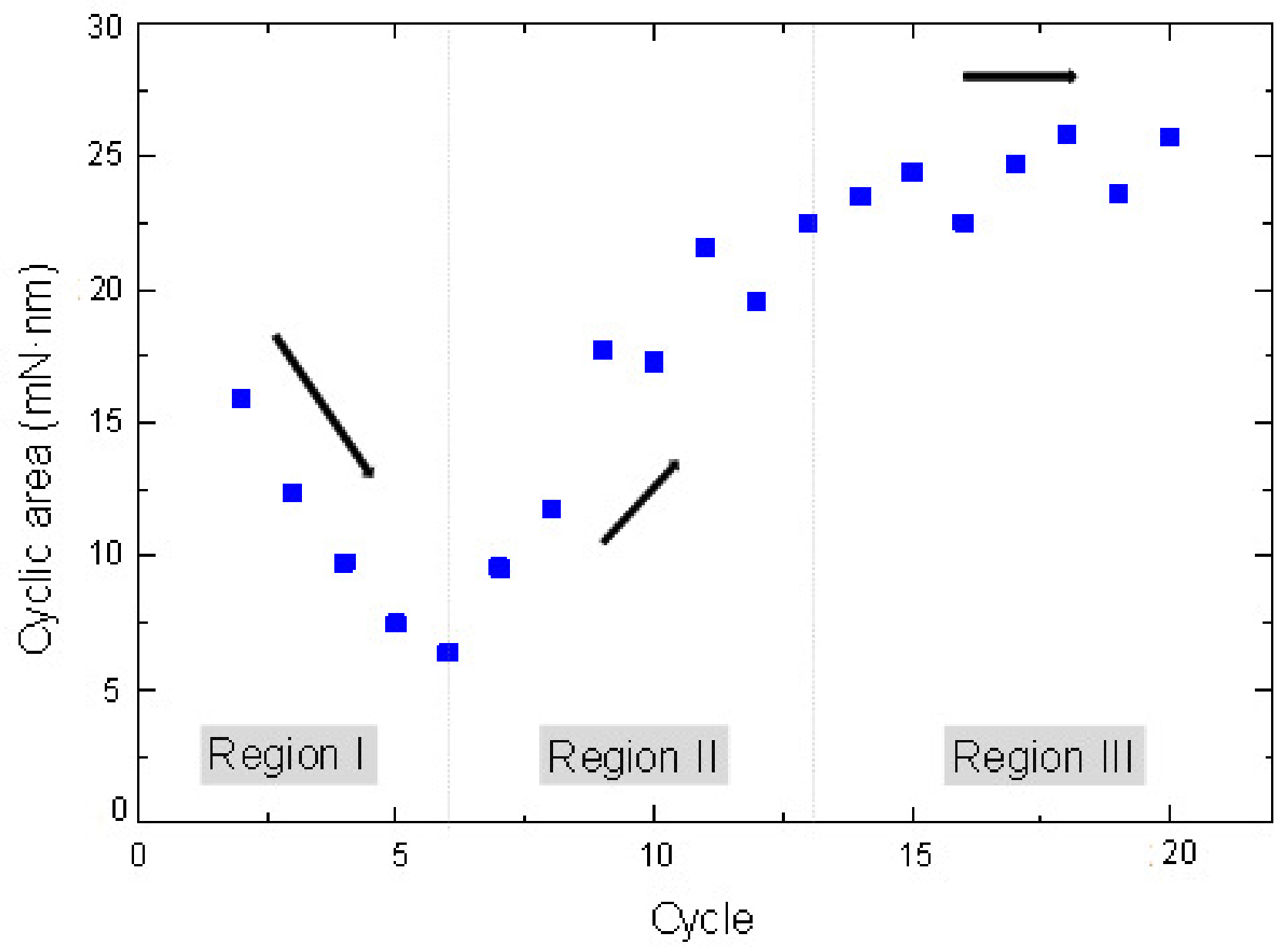




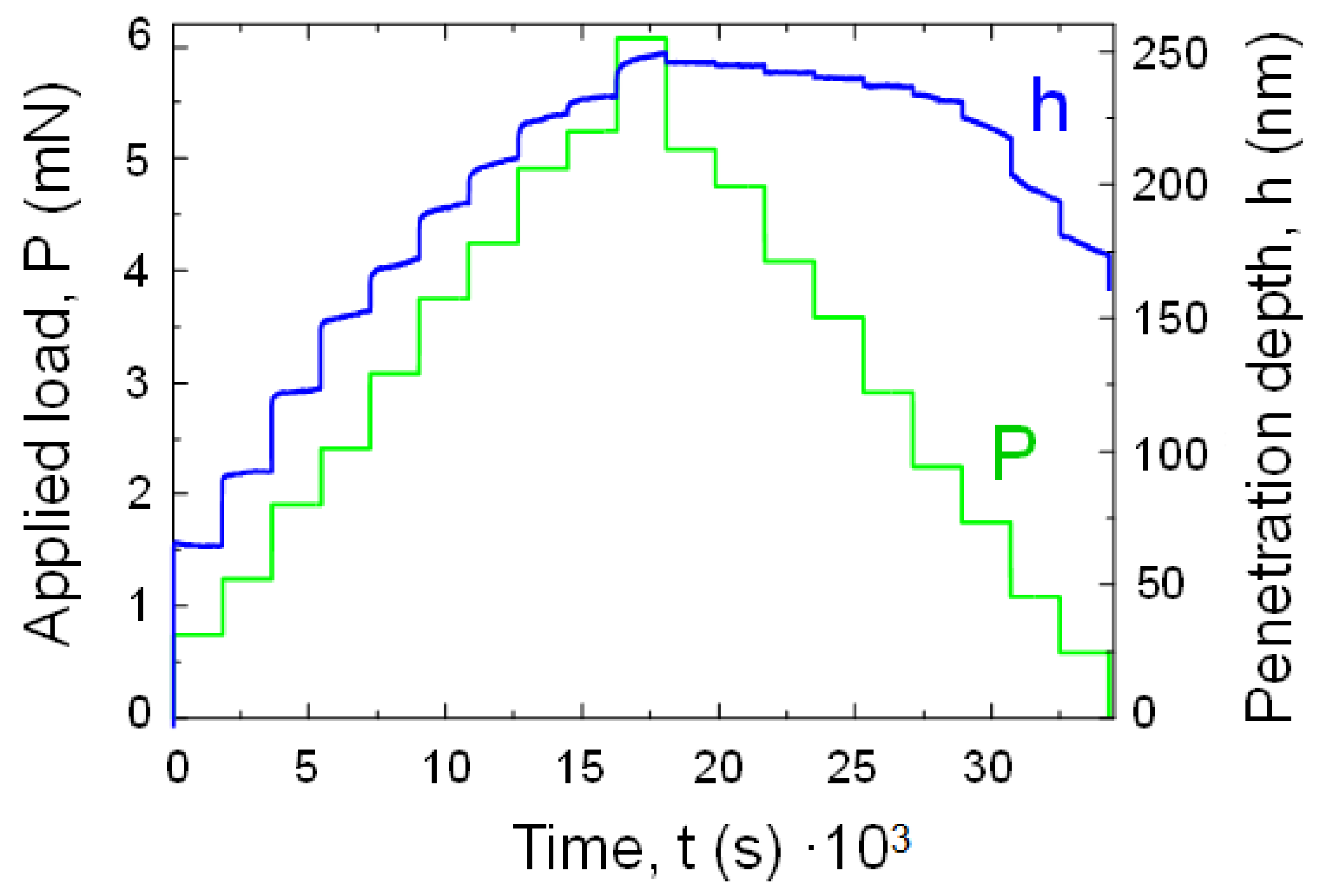




\section{Table captions}

Table 1. Chemical composition of the studied stainless steel AISI $301 \mathrm{LN}$ (wt. $\%$.). 
Table 1

\begin{tabular}{|c|c|c|c|c|c|c|c|c|}
\hline & $\mathbf{C}$ & $\mathbf{C r}$ & $\mathbf{N i}$ & $\mathbf{M n}$ & $\mathbf{S i}$ & Mo & $\mathbf{N}$ & $\mathbf{F e}$ \\
\hline AISI 301 LN & 0.02 & 17.48 & 7.03 & 1.23 & 0.45 & 0.12 & 0.12 & Bal. \\
\hline
\end{tabular}

